\title{
Análise do produto botox caps da life natural
}

\author{
Dr. Fabiano de Abreu Agrela Rodrigues ${ }^{1}$ \\ deabreu.fabiano@gmail.com
}

Daniela Lopez ${ }^{2}$

\section{RESUMO}

A pele é um dos órgãos mais importantes do corpo, devido ao fato de promover revestimento e termorregulação. Além de atuar no sistema sensorial, na defesa contra agressões externas, dentre outras. Com o desgaste natural, nossa pele perde alguns componentes básicos como: elastina e colágeno e, consequentemente, surgem as marcas do envelhecimento cutâneo. No entanto, existem ativos que podem beneficiar a saúde da pele. Sendo assim, o objetivo do presente estudo é avaliar os efeitos do produto Box Caps da empresa Life Natural. A metodologia utilizada para desenvolvimento foi a de revisão de literatura. Através de tal análise, foi possível compreender a eficácia do produto para a melhora da saúde da pele. Ou seja, nas rugas, linhas de expressão e manchas cutâneas. Portanto, a análise da ação contra o envelhecimento precoce.

Palavras-chave: pele, rejuvenescimento; botox; ácido hialurônico; colágeno; vitamina C

\footnotetext{
${ }^{1} \mathrm{PhD}$, neurocientista com formações também em neuropsicologia, biologia, história e antropologia deabreu.fabiano@gmail.com - Centro de Pesquisas e Análises Heráclito - Castelo de Paiva - Aveiro Portugal

${ }^{2}$ Especialista em estética e cosmetologia intradérmicas Representante da Sociedade Brasileira de Estética e Cosmetologia Escola Superior de Estética e Cosmetologia ESEC São Paulo - SP - Brasil
} 


\title{
Life Natural Botox Caps Product Review
}

\begin{abstract}
The skin is one of the most important organs, due to the fact that it promotes coating, thermoregulation, acts on the sensory system, in defense against external aggressions, among others. Over the years, our skin loses some components such as; elastin and collagen and consequently skin aging, but there are actives that can improve skin health. Therefore, the aim of this research is to evaluate the effects of the Box Caps product from the Life Natural company. The methodology used for development was the literature review. Through such analysis, it was possible to understand the effectiveness of the product, for the improvement of skin health, in wrinkles, expression lines and skin spots, preventing premature aging.
\end{abstract}

Keywords: skin; rejuvenation; botox; hyaluronic acid; collagen; vitamin c1.

Artículo recibido: 02 enero 2022 Aceptado para publicación: 28 enero 2022 Correspondencia: deabreu.fabiano@gmail.com Conflictos de Interés: Ninguna que declarar 


\section{INTRODUÇÃO}

\subsection{Pele e Envelhecimento}

Considerado um dos principais órgãos do corpo humano, atua como importante revestimento, termorregulação, atua no sistema sensorial, na defesa contra agressões externas, dentre outras (Kim, 2018).

É dividida em duas camadas. Sendo a primeira, a epiderme. Uma camada externa formada por extratos de células distintas devido sua morfologia, grau de maturação e profundidade. Ao mesmo tempo, as mais superficiais são caracterizadas como justapostas e cobertas por queratina. Por isso, leva o nome de tecido epitelial pavimentoso (ou escamoso) estratificado queratinizado. Tal camada não possuí vascularização (Kim, 2018).

A segunda camada denominada como derme, é responsável por $90 \%$ da espessura cutânea. Componentes como colágeno e a elastina, que são responsáveis pela elasticidade à pele, estão presentes nesta camada. Além do que, é aqui que se determina o padrão predominante de fibras de colágeno relacionadas à tensão característica e as rugas do tecido (Andrade, 2020).

As fibras elásticas da derme diminuem com o passar dos anos e não são substituídas. Sendo assim, nos indivíduos idosos, a pele apresenta rugas e flacidez pós-perda da elasticidade. Visto isso, a derme é um tecido conjuntivo que sustenta a epiderme. É composto através de elementos fibrilares, como o colágeno, elastina, proteínas estruturais, glicosaminoglicanos, íons, água de solvatação e outros elementos da matriz extracelular (Andrade, 2020).

Logo, o envelhecimento é formado a partir de alterações fisiológicas que surgem ao longo do tempo em organismos multicelulares. Tais alterações ocorrem nas moléculas e nas células que prejudicam o funcionamento dos órgãos e do organismo, de modo geral. As causas podem ser: genéticas, estilos de vida e o ambiente em que uma pessoa vive (Khavkin, 2011).

Já o envelhecimento cutâneo, está caracterizado clinicamente pela perda de elasticidade dos tecidos de alteração da textura da pele, aparecimento de anomalias superficiais como: pequenos vasos, manchas castanhas, além das rugas e linhas de expressão (Wang, 2019). Classicamente, assim como o envelhecimento intrínseco - aquele que ocorre a partir de um fenómeno natural que atinge todos os órgãos - e o envelhecimento extrínseco; 
devido a um conjunto de fatores que aceleram o envelhecimento natural tais como: exposição à radiação UV, tabaco, álcool, uso constante de maquiagem, não realizar skin care, dentre outros fatores (Khavkin, 2011).

\subsection{Ativos Cosméticos}

O Ácido Hialurônico é um dos principais componentes da matriz extracelular. O ativo convencional possui uma estrutura com alto peso molecular $(800 \mathrm{kDa})$, devido a este fato, sua permeação é dificultada na derme, sendo importante para manter a hidratação na epiderme. (Salwowska, 2016). Em contrapartida, o Ácido Hialurônico de origem vegetal possui um baixíssimo peso molecular $(8 \mathrm{kDa})$, o que maximiza as propriedades benéficas dessa molécula no organismo, com capacidade de permeação nas camadas mais profundas da pele (derme) (Hsu, 2009).

Atua na retenção de água na matriz intercelular do tecido conjuntivo, onde aumenta significativamente a elasticidade, hidratação e preenchimento da pele, suavizando rugas e linhas de expressão (Hsu, 2009).

Figura 1 - Estrutura molecular do ácido hialurônico

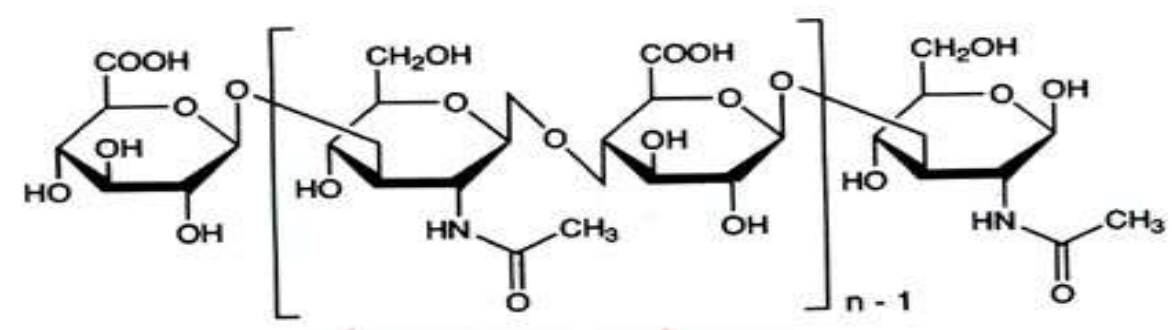

Fonte: Adaptado de Mendonça A. (2016)

Outro componente é a Biotina, conhecida como vitamina B7, caracterizada como essencial e hidrossolúvel, atua como uma coenzima no metabolismo das purinas e dos carboidratos. Sua falta no organismo pode gerar erupções cutâneas. Sua presença, favorece a hidratação e garante a formação de colágeno e queratina (Lipner, 2018).

Figura 2 - Estrutura molecular da biotina

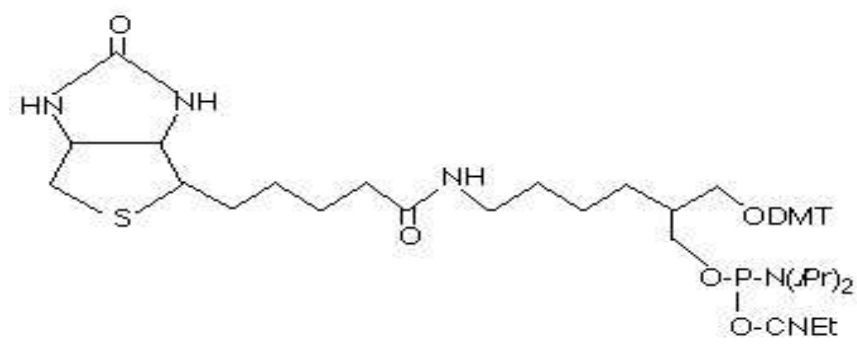

Fonte: Adaptado de Lima (2013) 
Vitamina $\mathrm{C}$, também conhecida como ácido ascórbico, encontrada em diversos alimentos e vendida como suplemento, é um potente antioxidante e auxilia na produção de colágeno Atuante na reparação do tecido e na produção enzimática de certos neurotransmissores. É eficaz no combate às manchas, inibidora do melasma, rugas e linhas de expressão (Gref, 2020).

Figura 3 - Estrutura molecular da vitamina $\mathrm{C}$

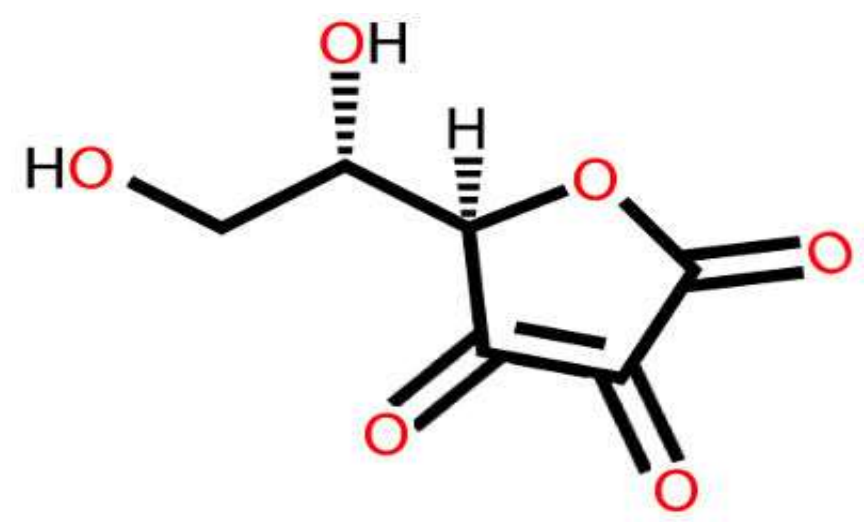

Fonte: Adaptado de Dias (2018)

Vitamina E, é um componente lipossolúvel e essencial, importante no funcionamento do organismo, pois possuí ação antioxidante e anti-inflamatória. Consequentemente, auxilia na melhora do sistema imune, atuando na prevenção de doenças como aterosclerose e o Alzheimer (Mohd, 2020).

Devido ao seu poder antioxidante, atua no combate dos radicais livres, assim, tal componente ajuda a proteger a pele contra tais danos, prevenindo o envelhecimento precoce, bem como o surgimento de rugas, melhora da cicatrização e algumas condições de pele, como a dermatite atópica, por exemplo (Mohd, 2020).

Figura 4 - Estrutura molecular da vitamina $\mathrm{E}$<smiles>Cc1c(C)c2c(c(C)c1O)CC[C@@](C)(CCCC(C)(C)CCCC(C)(C)CCCC(C)CF)O2</smiles>

Fonte: Adaptado de Lima (2013) 
Outra vitamina importante é a A, conhecida também como retinol, um micronutriente lipossolúvel. Seus principais benefícios são ação antioxidante, fortalecimento da imunidade e regeneração tecidual (Szymański, 2020).

Através do combate aos radicais livres, aceleram o envelhecimento celular. Isso significa que possuí ação antioxidante, assegurando a preservação de diversos tecidos, principalmente das células da pele, mucosas, olhos e ossos (Szymański, 2020).

É importante para que se tenha um sistema imunológico forte e saudável. Após sua absorção no organismo, promove o estímulo da produção de anticorpos, a capacidade do corpo de responder à presença de agentes invasores. Sendo assim, auxilia para que ocorra a identificação e adaptação ao combate de novos vírus, bactérias e outros microorganismos que entrarem em contato com o organismo (Kong, 2016).

A deficiência de vitamina A, pode ser associada a diversos problemas. Em adultos, a falta desse nutriente pode promover o aceleramento do envelhecimento das células, aumentando a incidência de diferentes tipos de câncer e doenças cardiovasculares, além de expor o organismo à infecções frequentes (Kong, 2016).

Figura 5 - Estrutura molecular da Vitamina A

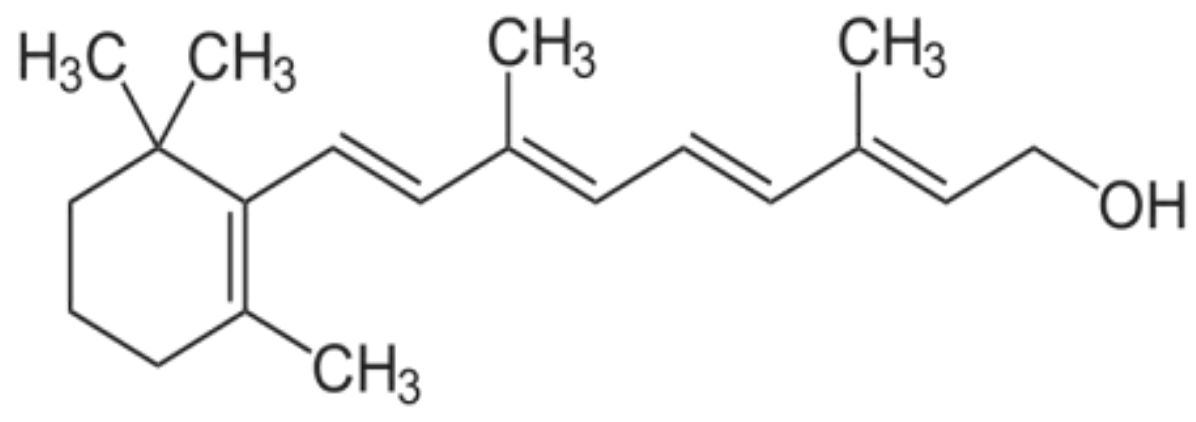

Fonte: Adaptado de Lima (2013)

O colágeno é uma proteína fibrosa, estrutural e de origem animal, encontrada na matriz extracelular, responsável por formar fibras resistentes. É a proteína mais abundante do reino animal, presente, principalmente, nos tecidos conjuntivos e ósseos. No corpo humano, o colágeno corresponde a cerca de $40 \%$ das proteínas (Bolke, 2019).

Responsável por manter a estrutura, a firmeza e a elasticidade da pele, auxiliando na prevenção da flacidez tissular, rugas, linhas de expressão, estrias (Bolke, 2019). 
Figura 6 - Estrutura molecular do colágeno.

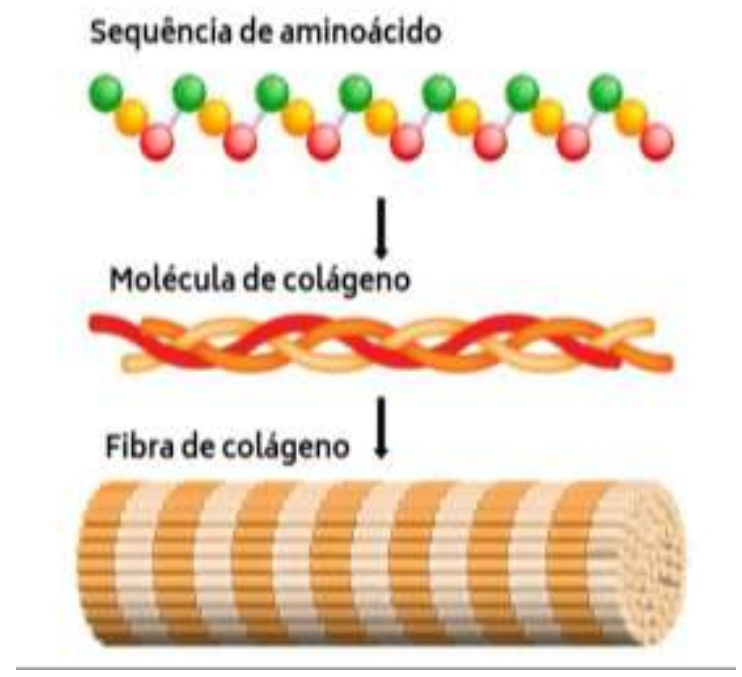

Fonte: https://www.biologianet.com/biologia-celular/colageno.htm

\section{OBJETIVO}

- Avaliar os efeitos do produto Box Caps da empresa Life Natural ${ }^{\circledR}$

\section{METODOLOGIA}

O presente estudo se trata de uma revisão de literatura realizada por meio das seguintes bases de dados: PubMed, Scielo e Google Acadêmico através das seguintes palavraschave: pele, rejuvenescimento, botox, ácido hialurônico, colágeno, vitamina c. Em inglês: skin, rejuvenation, botox, hyaluronic acid, collagen, vitamin c. Bem como, a bula do produto chá solúvel hibisco e através das informações passadas pelo fabricante do mesmo: Life Natural ${ }^{\circledR}$.

\section{RESULTADOS}

O produto Botox Caps da empresa Life Natural ${ }^{\circledR}$, que utiliza componentes naturais (Ácido Hialurônico Vegetal, Biotina, Vitamina C, Vitamina E, Vitamina A e o Colágeno Hidrolisado).

Atua na origem do processo de envelhecimento da pele e age na renovação celular. Desta forma, impacta no envelhecimento precoce, na recuperação da firmeza da pele e prevenção da flacidez que, com a idade, se torna normal. Além disso, o Botox Caps promove em conjunto a hidratação da pele e a redução das manchas.

Para obter um bom resultado, o fabricante recomenda a ingestão de 1 capsula ao dia após as principais refeições. A seguir a bula do Botox Caps com todas as informações passadas pelo fabricante: 


\begin{tabular}{|l|c|c|}
\hline \multicolumn{1}{|c|}{ TABELA NUTRICIONAL } & QTD. /DOSE & \% VD* \\
\hline VALOR ENERGÉTICO & $1,2 \mathrm{kcal}$ & $*$ \\
\hline Ácido Hialurônico & $150 \mathrm{mg}$ & $*$ \\
\hline Proteínas & $0,3 \mathrm{~g}$ & $45 \%$ \\
\hline Vitamina C & $45 \mathrm{mg}$ & $67 \%$ \\
\hline Vitamina E & $10 \mathrm{mg}$ & $75 \%$ \\
\hline Vitamina A & $600 \mathrm{mcg}$ & $15 \%$ \\
\hline Biotina & $45 \mathrm{mcg}$ & \\
\hline
\end{tabular}

*Não contém quantidades significativas de valor Energético, Carboidratos, Proteínas, Gorduras Totais, Gorduras Saturadas, Gorduras Trans, Fibra Alimentar e Sódio

Sendo indicado para indivíduos maiores de 19 anos e contraindicado para gestantes, lactantes e crianças.

\section{CONSIDERAÇÕES FINAIS}

Através da análise da composição do produto, usando como referência os dados enviados pela empresa Life Natural.

É possível afirmar a eficácia do produto Botox Caps da Life Natural ${ }^{\circledR}$, o mesmo contém substâncias que possuem comprovação científica através da publicação na revista científica e no Centro de Pesquisas e Análises Heráclito - CPAH Scientific Journal of Health. Portanto, há confirmação da eficácia para a melhoria da saúde da pele (rugas, linhas de expressão e manchas cutâneas) prevenindo o envelhecimento precoce.

\section{REFERENCIAS}

ANDRADE, N.N., Aggarwal, N., Mathai, P., Nerurkar, S., Desai, H., Gupta, V. Is dermis fat arthroplasty better than plain gap arthroplasty? A prospective randomised controlled trial. Br J Oral Maxillofac Surg. n. 58, v. 8, págs. 970-974, 2020 doi: 10.1016/j.bjoms.2020.04.045.

BOLKE, L., Schlippe, G., Gerß, J., Voss, W. A Collagen Supplement Improves Skin Hydration, Elasticity, Roughness, and Density: Results of a Randomized, Placebo-Controlled, Blind Study. Nutrients. n. 17, v. 11, e2494, 2019 doi: 
10.3390/nu11102494.

DIAS, D. L. Ácido ascórbico (Vitamina C). Manual da química, 2018.

GREF, R., Deloménie, C., Maksimenko, A., Gouadon, E., Percoco, G., Lati, E., Desmaële, D., Zouhiri, F., Couvreur, P. Vitamin C-squalene bioconjugate promotes epidermal thickening and collagen production in human skin. Sci Rep. n. 9, v. 10, e16883, 2020 doi: 10.1038/s41598-020-72704-1.

KHAVKIN, J., Ellis, D.A. Aging skin: histology, physiology, and pathology. Facial Plast Surg Clin North Am. n. 19, v. 2, págs. 229-34, 2011 doi: 10.1016/j.fsc.2011.04.003.

KIM, D.U., Chung, H.C., Choi, J., Sakai, Y., Lee, B.Y. Oral Intake of Low-MolecularWeight Collagen Peptide Improves Hydration, Elasticity, and Wrinkling in Human Skin: A Randomized, Double-Blind, Placebo-Controlled Study. Nutrients. n. 26, v. 10, e7, 2018 doi: 10.3390/nu10070826.

KONG, R., Cui, Y., Fisher, G.J., Wang, X., Chen, Y., Schneider, L.M., Majmudar, G. A comparative study of the effects of retinol and retinoic acid on histological, molecular, and clinical properties of human skin. J Cosmet Dermatol. n. 15, v. 1, págs. 49-57, 2016 doi: 10.1111/jocd.12193.

LIMA, A.P.O. Biotina. InfoEscola, 2013.

LIPNER, S.R. Rethinking biotin therapy for hair, nail, and skin disorders. J Am Acad Dermatol. n. 78, v. 6, págs. 1236-1238, 2018 doi: 10.1016/j.jaad.2018.02.018.

MENDONÇA, A. Ácido Hialurônico - promove rearquitetura facial, preenchimento e hidratação profunda. Adélia Mendonça, 2016.

MOHD, Z.A.S, Hassan, H., Alias, E. Pharmacology and Pharmacokinetics of Vitamin E: Nanoformulations to Enhance Bioavailability. Int J Nanomedicine. n. 8, v. 15, págs. 9961-9974, 2020 doi: 10.2147/IJN.S276355.

SALWOWSKA, N.M., Bebenek, K.A., Żądło, D.A., Wcisło-Dziadecka, D.L. Physiochemical properties and application of hyaluronic acid: a systematic review. J Cosmet Dermatol. n.15, v. 4, págs. 520-526, 2016 doi: 10.1111/jocd.12237.

SZYMAŃSKI, Ł., Skopek, R., Palusińska, M., Schenk, T., Stengel, S., Lewicki, S., Kraj, L., Kamiński, P., Zelent, A. Retinoic Acid and Its Derivatives in Skin. Cells. n. 11, v. 9, e2660, 2020 doi: 10.3390/cells9122660. 
WANG, Y., Wang, L., Wen, X., Hao, D., Zhang, N., He, G., Jiang, X. NF-кB signaling in skin aging. Mech Ageing Dev. n.184, e111160, 2019 doi: 10.1016/j.mad.2019.111160. 